\title{
Geotecnologias aplicadas à análise da fragilidade ambiental na sub- bacia hidrográfica do Arroio Pessegueiro - RS
}

\author{
Geotechnologies applied to the analysis of the environmental fragility in the sub- \\ basin of Arroio Pessegueiro - RS \\ Geotecnologías aplicadas al análisis de la fragilidad ambiental en la subcuenca \\ hidrográfica del Arroyo Pessegueiro - RS
}

Bruna Andrieli Simões de Oliveira Engenheira Florestal, UFSM, Santa Maria - RS Brasil. brunasimoess@hotmail.com

\section{Roberta Aparecida Fantinel} Engenheira Florestal, UNIPAMPA, São Gabriel - RS, Brasil. fantinel.ar@gmail.com

Juliana Marchesan Doutoranda em Engenharia Florestal, UFSM, Brasil. marchesan.ju@gmail.com

\section{Rudiney Soares Pereira} Professor Doutor, UFSM, Santa Maria - RS Brasil. rudiney.s.pereira@gmail.com 


\section{RESUMO}

A fragilidade ambiental está relacionada aos ambientes em situação de risco, causada pelas condições naturais somadas às contribuições das ações antrópicas, desta forma o objetivo do trabalho foi mapear as áreas de fragilidade ambiental da sub-bacia hidrográfica do Arroio Pessegueiro - RS, integrando as variáveis uso e cobertura da terra, solo, geologia, geomorfologia e declividade, caracterizando as áreas de fragilidade ambiental potencial e emergente. Adotou-se a proposta de ROSS (1994), no qual atribui o grau de fragilidade que foram classificadas em cinco diferentes níveis: muito baixa (1), baixa (2), média (3), alta (4) e muito alta (5). A fragilidade potencial muito alta e alta totalizaram $2.854,70$ ha e $2.607,52$ ha respectivamente. Enquanto, na análise da fragilidade emergente observou-se o predomínio da fragilidade média com 3.764,04ha, seguida da alta com 2.538,22ha. 0 uso das geotecnologias foi fundamental para o desenvolvimento do estudo, uma vez que, por meio das imagens de satélite foi possível obter o mapa de uso e cobertura da terra, bem como realizar a álgebra de mapas, no qual se mostrou eficaz para identificação da influência de cada componente no mapa final da fragilidade ambiental potencial e emergente.

PALAVRAS-CHAVE: Fragilidade Potencial. Fragilidade Emergente. Geoprocessamento.

\section{SUMMARY}

The environmental fragility is related to the environments at risk, caused by the natural conditions added to the contributions of the anthropic actions, in this way the objective of the work was to map the areas of environmental fragility of the Arroio Pessegueiro - RS sub-basin, integrating the variables use and land cover, soil, geology, geomorphology and declivity, characterizing the areas of potential and emerging environmental fragility. The proposal of ROSS (1994) was adopted, in which it attributes the degree of fragility that were classified into five different levels: very low (1), low (2), medium (3), high (4) and very high 5). The very high and high potential fragility totaled $2,854,70$ ha and $2,607,52$ ha respectively. While, in the analysis of the emergent fragility, it was observed the predominance of the average fragility with $3,764.04 \mathrm{ha}$, followed by the high with $2,538,22 \mathrm{ha}$. The use of geotechnologies was fundamental for the development of the study, since, through the satellite images, it was possible to obtain the map of land use and cover, as well as to perform map algebra, in which it proved effective for identification of the influence of each component on the final map of potential and emerging environmental fragility.

KEY WORDS: Potential Fragility. Emergent Fragility. Geoprocessing.

\section{RESUMEN}

A fragilidad ambiental está relacionada a los ambientes en situación de riesgo, causada por las condiciones naturales sumadas a las contribuciones de las acciones antrópicas, de esta forma el objetivo del trabajo fue mapear las áreas de fragilidad ambiental de la subcuenca hidrográfica del Arroyo Pessegueiro - RS, integrando las variables uso y cobertura de la tierra, suelo, geología, geomorfología y declividad, caracterizando las áreas de fragilidad ambiental potencial y emergente. Se adoptó el Ross propuesto (1994), que asigna el grado de fragilidad que se han clasificado en cinco niveles: muy pobre (1) pobre (2), medio (3), alto (4) y muy alta ( 5). La fragilidad potencial muy alta y alta totalizó $2.854,70$ ha y $2.607,52$ ha respectivamente. Mientras, en el análisis de la fragilidad emergente se observó el predominio de la fragilidad media con $3.764,04 \mathrm{ha}$, seguida del alza con $2.538,22 \mathrm{ha}$. E uso de las geotecnologías fue fundamental para el desarrollo del estudio, ya que, por medio de las imágenes de satélite fue posible obtener el mapa de uso y cobertura de la tierra, así como realizar la álgebra de mapas, en el cual se mostró eficaz para identificación de la geografía influencia de cada componente en el mapa final de la fragilidad ambiental potencial y emergente.

PALABRAS CLAVE: Fragilidad Potencial. Fragilidad emergente. Geoprocesamiento. 


\section{INTRODUÇÃO}

As ações antrópicas de forma excessiva e sem planejamento dos usos dos recursos naturais, têm contribuído para o agravamento dos impactos ambientais nas últimas décadas. Desta forma, conhecer as formas do uso do solo, seu monitoramento e o registro das informações quanto a fragilidade ambiental é fundamental, pois permitem o planejamento e a avaliação das potencialidades futuras e dos impactos produzidos por estes usos. Logo, o planejamento ambiental precisa ser considerado um processo contínuo, no qual devem ser levantadas e diagnosticadas as condições ambientais de uma determinada área, com propósito de utilizar os recursos naturais disponíveis de forma mais racional e não predatória (SILVA, 2001).

De acordo com Batista e Silva (2013) a fragilidade ambiental está relacionada aos ambientes em situação de risco, causada pelas condições naturais somadas às contribuições das ações antrópicas, provocadas pelo uso e ocupação da terra. Seguindo este mesmo pensamento, Ross et al. (2005) destacam que a fragilidade ambiental se trata da vulnerabilidade natural associada aos níveis de proteção que os diferentes tipos de uso e cobertura vegetal exercem. Por meio de mapeamentos é possível averiguar as alterações do uso e cobertura da terra de uma determinada área, além de otimizar suas potencialidades, de forma integrada para buscar o equilíbrio ambiental, econômico e social. Como parte integrada às geotecnologias, surgem o Sensoriamento Remoto, Geoprocessamento e os Sistemas de Informações Geográficas (SIG's).

Dentre as tecnologias mais abordadas em pesquisas voltadas à análise da dinâmica do uso e cobertura da terra, destaca-se o Sensoriamento Remoto, devido ao seu produto mais conhecido, as imagens de satélites. $\mathrm{O}$ uso do Sensoriamento Remoto possibilita aplicações nas áreas de levantamentos de recursos naturais e mapeamentos temáticos, monitoração ambiental, deteç̧ão de desastres naturais, desmatamentos, previsões de safras, cadastramentos multifinalitários, cartografia de precisão, defesa e vigilância, entre outras (MENESES e ALMEIDA, 2012).

As ferramentas de Geoprocessamento, segundo Padilha (2008), são eficazes no estudo da fragilidade ambiental, uma vez que, permitem que sejam realizadas análises, planejamento e monitoramento de áreas naturais. O Geoprocessamento, para Rosa e Brito (1996, p. 7), "é conjunto de tecnologias destinado à coleta e tratamento de informações espaciais, assim com o desenvolvimento de novos sistemas e aplicações, com diferentes níveis de sofisticação". O Geoprocessamento, ainda de acordo com Moreira (2005) é a utilização de técnicas matemáticas e computacionais para tratar dados e objetos ou fenômenos geograficamente identificados ou, extrair informações destes objetos ou fenômenos quando eles são observados por um sistema sensor.

Referente aos SIG's, estes podem ser definidos como sistemas destinados ao tratamento automatizado de dados georreferenciados, provenientes de diversas fontes e formatos, dentro de um ambiente computacional ágil e capaz de integrar as informações espaciais temáticas e gerar novos dados derivados dos originais (ASSAD e SANO, 1998). Os SIG's têm como característica principal a possibilidade de inserir e integrar em um único banco de dados informações espaciais provenientes de dados cartográficos, dados censitários e 
cadastro (urbano e rural), imagens de satélite, redes e modelos numéricos de terreno (CÂMARA e MEDEIROS, 1996).

\section{OBJETIVO}

O presente trabalho teve como objetivo mapear as áreas de fragilidade ambiental da subbacia hidrográfica do Arroio Pessegueiro - RS, integrando as variáveis uso e cobertura da terra, solo, geologia, geomorfologia e declividade, caracterizando as áreas de fragilidade ambiental potencial e emergente.

\section{METODOLOGIA}

\subsection{CARACTERIZAÇÃO DA ÁREA DE ESTUDO}

A sub-bacia hidrográfica do Arroio Pessegueiro integra a bacia hidrográfica do Rio Jaguari, no qual estão inseridos os municípios de Jaguari, Jari e Mata, ocupando uma área de 8.407,38 hectares. Situa-se na região centro oeste do Estado do Rio Grande do Sul, entre as coordenadas geográficas 2938'83'" e 2946'58' latitude Sul, e 5451'23" e 5436'52" longitude Oeste (Figura 1).

Figura 1: Localização da sub-bacia hidrográfica do Arroio Pessegueiro - RS.

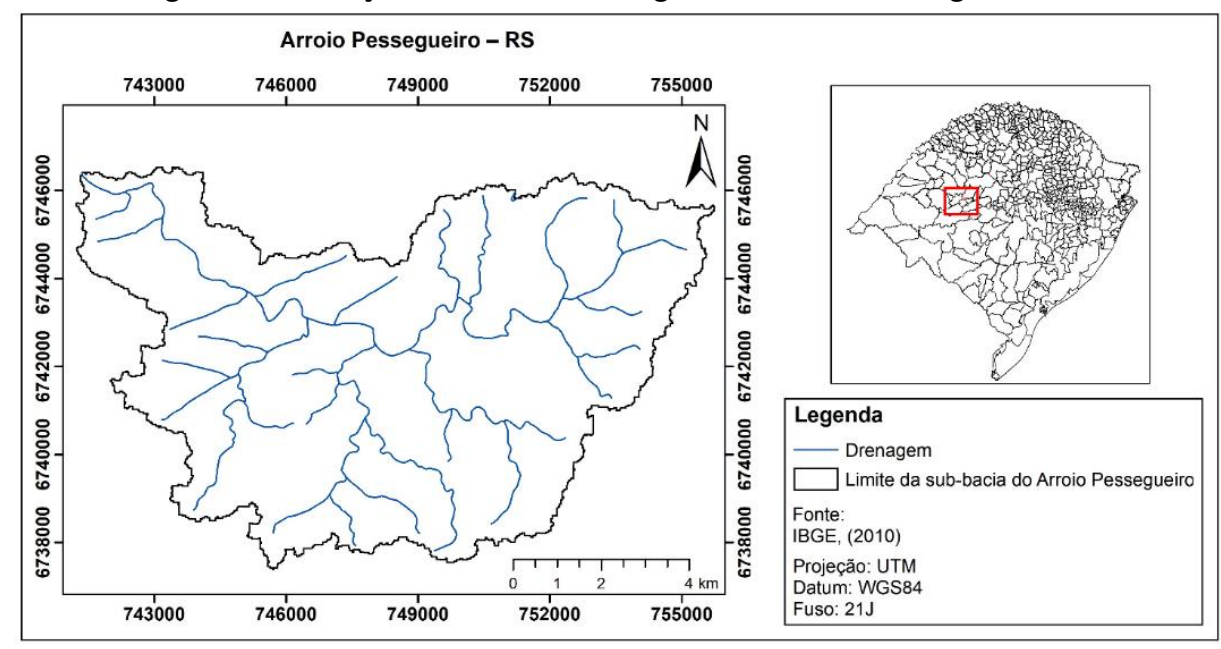

De acordo com a classificação de Köppen o clima da região é subtropical úmido (Cfa), com temperaturas que variam entre $14^{\circ} \mathrm{C}$ e $25^{\circ} \mathrm{C}$, as precipitações, por sua vez, são distribuídas durante o ano, apresentando média anual de 1.700mm (ALVARES et al., 2013).

A vegetação predominante na região é denominada de Floresta Estacional Decidual, porém, atualmente, encontra-se apenas remanescentes dessa formação nativa (MARCHIORI, 2002). De acordo com a Companhia de Pesquisas de Recursos Minerais (CPRM, 2008) a geologia presente na área de estudo é as fácies gramado, caracterizada por derrames basálticos. No que se refere ao solo, a sub-bacia hidrográfica do Arroio Pessegueiro segundo a Embrapa 
(2011), destaca-se o neossolo litólicos eutróficos - Rle27. A geomorfologia é destacada pela Serra Geral e Planalto dos Campos Gerais (IBGE, 2018).

\subsection{OBTENÇÃO DOS DADOS E PROCESSAMENTO DAS IMAGENS}

A imagem utilizada para a classificação do uso e cobertura da terra foi do satélite Sentinel$2 \mathrm{~A}$, sensor MSI (Multi-Spectral Instrument), com resolução espacial de 10 metros, adquirida gratuitamente por meio do United States Geological Survey (USGS), datada em 31 de janeiro de 2017. A classificação digital da imagem foi realizada na extensão, para classificação supervisionada semiautomática, SCP (Semi-Automatic Classification Plugin), incorporada no software QGis versão 2.18 .

Posteriormente ajustou-se as bandas para a obtenção da composição verdadeira com base nas bandas 4, 3, 2 (RGB), sendo estas contrastadas a fim de proporcionar melhor conforto visual na identificação dos alvos presentes na imagem. Para a classificação supervisionada utilizou-se o classificador Máxima Verossimilhança (Maxver), adquirindo as amostras nas diferentes classes temáticas: floresta, campo, agricultura, água e solo exposto. As áreas de proteção do solo pela cobertura vegetal foram analisadas de acordo com a proposta de Ross (1994), descritas na Tabela 1.

Tabela 1: Graus de proteção do solo pela cobertura vegetal.

\begin{tabular}{c|c|l}
\hline Valor & Grau de proteção & \multicolumn{1}{|c}{ Tipos de cobertura } \\
\hline 1 & Muito alta & $\begin{array}{l}\text { Florestas/Matas naturais, florestas cultivadas com } \\
\text { biodiversidade. }\end{array}$ \\
\hline 2 & Alta & Formações arbustivas naturais e densas. \\
\hline 3 & Média & Pastagens com baixo pisoteio de gado. \\
\hline 4 & Baixa & Água. \\
\hline 5 & Muito baixa & $\begin{array}{l}\text { Áreas desmatadas e queimadas recentemente; solo } \\
\text { exposto por arado/gradeado, solo exposto ao longo } \\
\text { de caminhos e estradas, terraplenagens, culturas } \\
\text { de ciclo curto sem práticas conservacionista. }\end{array}$ \\
\hline
\end{tabular}

Fonte: ROSS, 1994).

O modelo digital de elevação (MDE) foi obtido a partir da imagem de radar SRTM (Shuttle Radar Topography Mission), abordo do ônibus espacial Endeavour, com resolução espacial de $30 \mathrm{~m}$. As imagens SRTM foram inicialmente mosaicadas, após foram utilizadas para a delimitação automática da área de estudo, no qual foi realizada no software Qgis versão 2.14, por meio de módulos integrados com o programa GRASS (Watershed). Referente a classificação da declividade, as classes foram adaptadas, conforme a metodologia proposta por Ross (1994) e Embrapa (2011) (Tabela 2). 
Tabela 2: Graus de fragilidade de acordo com a declividade.

\begin{tabular}{c|c|c|c}
\hline Valor & Grau de fragilidade & Declividade & Descrição \\
\hline 1 & Muito baixa & $0-3 \%$ & Plano \\
\hline 2 & Baixa & $3-8 \%$ & Suave ondulado \\
\hline 3 & Média & $8-20 \%$ & Ondulado \\
\hline 4 & Alta & $20-45 \%$ & Forte ondulado \\
\hline 5 & Muito alta & $45-75 \%$ & Montanhoso \\
\hline
\end{tabular}

Fonte: ROSS, 1994 e EMBRAPA, 2011.

A tipologia do solo da área de estudo foi classificada de acordo com proposta da Embrapa (2011). Para classificar os graus de fragilidade dos solos utilizou-se o método proposto por Ross (1994), de acordo com a tabela 3.

Tabela 3: Graus de fragilidade de acordo com a classificação do solo.

\begin{tabular}{c|c|c}
\hline Valor & Grau de fragilidade & Tipos de solo \\
\hline 1 & Muito baixa & $\begin{array}{c}\text { Latossolo Bruno, Latossolo Roxo, Latossolo } \\
\text { Vermelho escuro e Vermelho Amarelo textura } \\
\text { argilosa. }\end{array}$ \\
\hline 2 & Baixa & $\begin{array}{c}\text { Latossolo Amarelo e Vermelho Amarelo } \\
\text { textura média/argilosa. }\end{array}$ \\
\hline 3 & Média & $\begin{array}{c}\text { Latossolo Vermelho Amarelo, Argilosos, } \\
\text { Alissolos textura média/argilosa }\end{array}$ \\
\hline 4 & Alta & $\begin{array}{c}\text { Argissolos textura média/arenosa, } \\
\text { Cambissolo. }\end{array}$ \\
\hline 5 & Muito alta & Neossolos, Organossolos. \\
\hline
\end{tabular}

Fonte: ROSS, 1994.

\section{3 ÁLGEBRA DE MAPAS}

Baseando na metodologia de Ross (1994) foram elaborados os mapas base sendo eles, o mapa de uso e ocupação da terra, declividade, geologia, geomorfologia e de solos. Para execução dos cruzamentos entre os diferentes planos de informação bem como sua representação nos respectivos mapas, foi realizada a hierarquização das suas classes e atribuído a elas valores (pesos) de fragilidade de acordo com a proposta de Ross (1994).

A partir dos mapas elaborados foram definidas cinco classes de fragilidade (pesos de importância) sendo elas: muito baixa - peso 1 , baixa - peso 2, média- peso 3 , alta - peso 4 e muito alta - peso 5; após fez-se o processamento de todos os planos de informação para obter a fragilidade ambiental potencial e fragilidade ambiental emergente, da sub-bacia hidrográfica do Arroio Pessegueiro, através de operações algébricas em ambiente SIG. 


\section{RESULTADOS}

O grau de fragilidade para o neossolo litólicos eutróficos de acordo com Ross (1994) é considerado como muito alta (peso 5), (Figura 2). O neossolo litólicos eutróficos são solos rasos, com baixa capacidade de infiltração e armazenamento de água no solo, possuem alta suscetibilidade à erosão hídrica, por isso, recomenda-se que áreas com declividade superior a $30 \%$ sejam conservadas com vegetação natural (STRECK et al., 2008).

Figura 2: Solo da sub-bacia hidrográfica do Arroio Pessegueiro - RS.

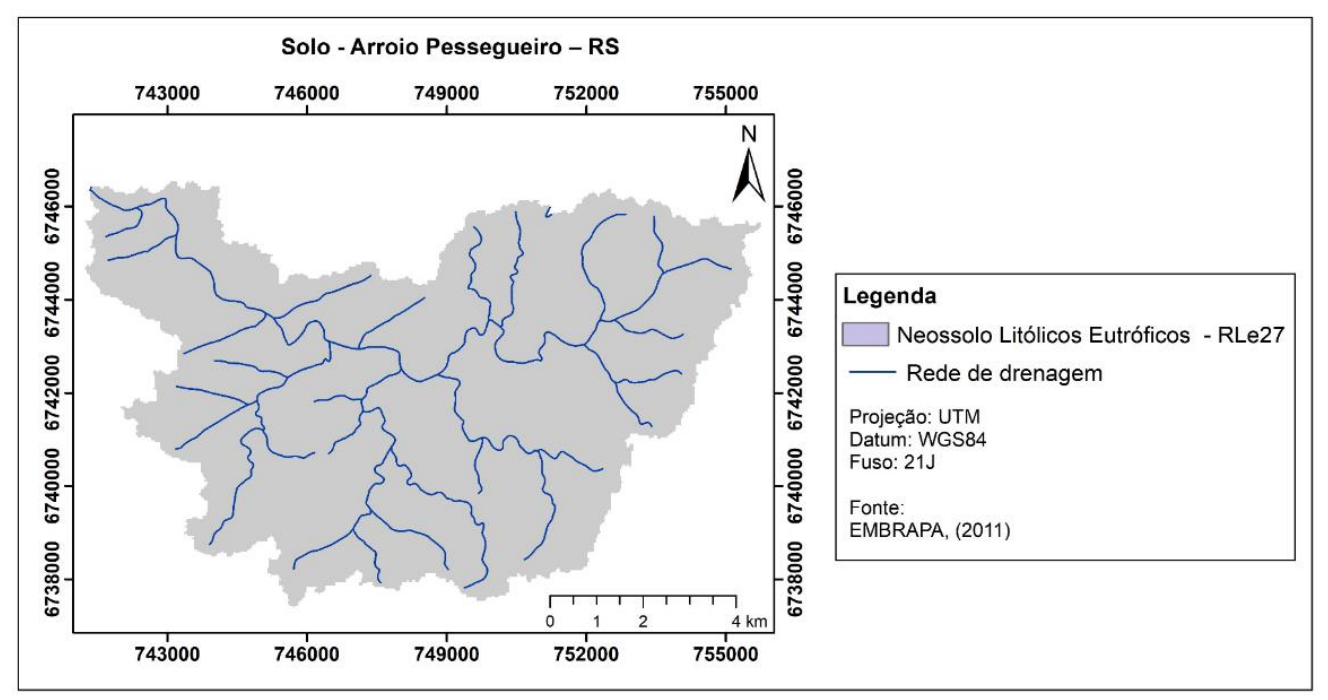

Após o processamento do MDE foram quantificadas as áreas pertencentes a cada classe de declividade, sendo posteriormente reclassificada em cinco níveis de fragilidade (Figura 3). $\mathrm{Na}$ Tabela 4 é possível averiguar a relação das categorias hierárquicas da fragilidade conforme a proposta de Ross (1994), sendo as classes baixa e média as mais significativas na área do estudo, totalizando $72,31 \%$. 
Tabela 4 Fragilidade ambiental das classes de declividade - Arroio Pessegueiro.

\begin{tabular}{c|c|c|c}
\hline Fragilidade & Classes de declividade & Área (ha) & Percentual (\%) \\
\hline 1-Muito baixa & $0-3 \%$ & $1.249,87$ & 14,87 \\
\hline 2-Baixa & $3 \%-8 \%$ & $3.540,34$ & 42,11 \\
\hline 3-Média & $8 \%-20 \%$ & $2.539,20$ & 30,20 \\
\hline 4-Alta & $20 \%-45 \%$ & 970,33 & 11,54 \\
\hline 5-Muito alta & $45 \%-75 \%$ & 107,64 & 1,28 \\
\hline Total & - & $\mathbf{8 . 4 0 7 , 3 8}$ & $\mathbf{1 0 0}$ \\
\hline
\end{tabular}

Figura 3: Declividade da sub-bacia hidrográfica do Arroio Pessegueiro - RS.

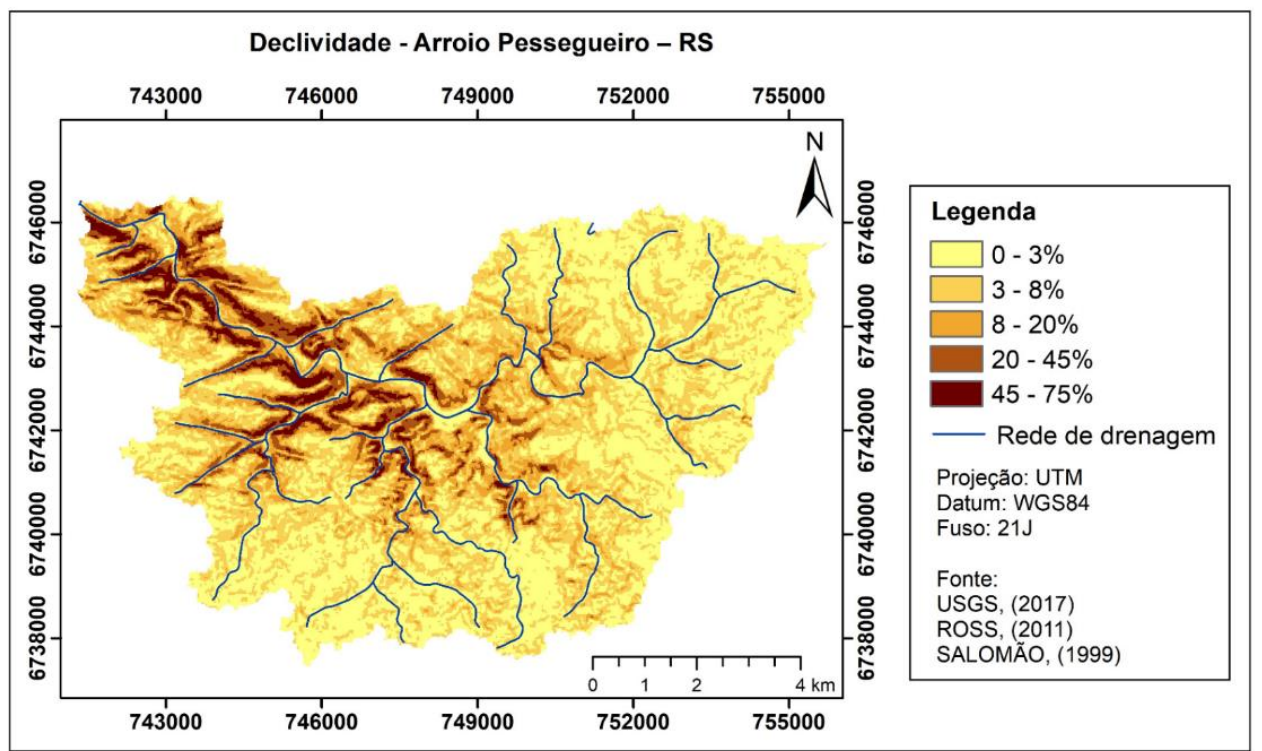

O mapeamento temático do uso e cobertura da terra constatou-se que dos $8.407,38$ ha da sub-bacia hidrográfica do Arroio Pessegueiro, a classe floresta e campo são as mais representativas, totalizando 6.473,73ha da área total do estudo (Tabela 5) (Figura 4). 
Tabela 5: Quantificação das classes temáticas, sub-bacia hidrográfica do Arroio Pessegueiro.

\begin{tabular}{c|c|c}
\hline Classes & Área (ha) & Percentual (\%) \\
\hline Floresta & $3.679,39$ & 43,76 \\
\hline Agricultura & $1.211,02$ & 14,40 \\
\hline Solo exposto & 700,8 & 8,34 \\
\hline Campo & $2.794,34$ & 33,24 \\
\hline Água & 21,83 & 0,26 \\
\hline Total & $\mathbf{8 . 4 0 7 , 3 8}$ & $\mathbf{1 0 0}$ \\
\hline
\end{tabular}

As florestas possuem grau de proteção do solo muito alta, pois grande parte da água da chuva fica retida nas folhas das árvores, evitando assim que a água caia diretamente no solo, possibilitando uma infiltração mais lenta nas camadas subsuperficiais, além de minimizar o impacto da gota da chuva devido a matéria orgânica depositada no solo (NASCIMENTO et al., 2016).

Para Ross et al. (2005), as florestas naturais exercem grau de proteção muito forte sobre o ambiente, mantendo o equilíbrio dinâmico. A classe campo, por possuir uma vegetação rasteira considerou-se o grau de proteção do solo como alta.

Os solos expostos, sem a presença da cobertura vegetal, para Nascimento et al. (2016), ocasionam a degradação destes e intensificam os processos erosivos que aliados aos eventos pluviométricos tornam essas áreas extremamente desprotegidas.

Figura 4: Uso e cobertura da terra na sub-bacia hidrográfica do Arroio Pessegueiro - RS.

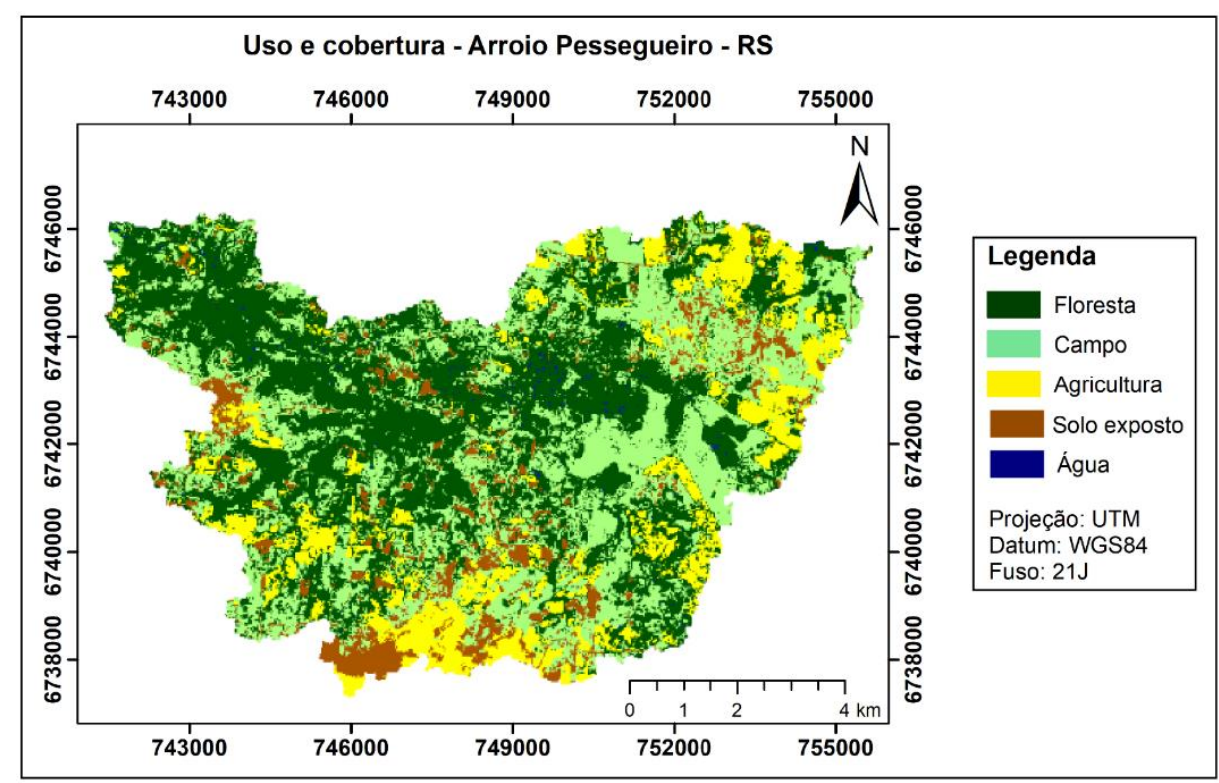

A geologia presente na sub-bacia hidrográfica do Arroio Pessegueiro é a fácies Gramado. Esta fácies tem sua área ao longo da escarpa sul da Serra Geral, marcada por um conjunto de derrames com espessura máxima em torno de 300 metros, no qual representam as primeiras 
manifestações vulcânicas sobre os sedimentos arenosos do então deserto Botucatu (CPRM, 2018) (Figura 5).

Figura 5 Geologia da sub-bacia hidrográfica do Arroio Pessegueiro - RS.

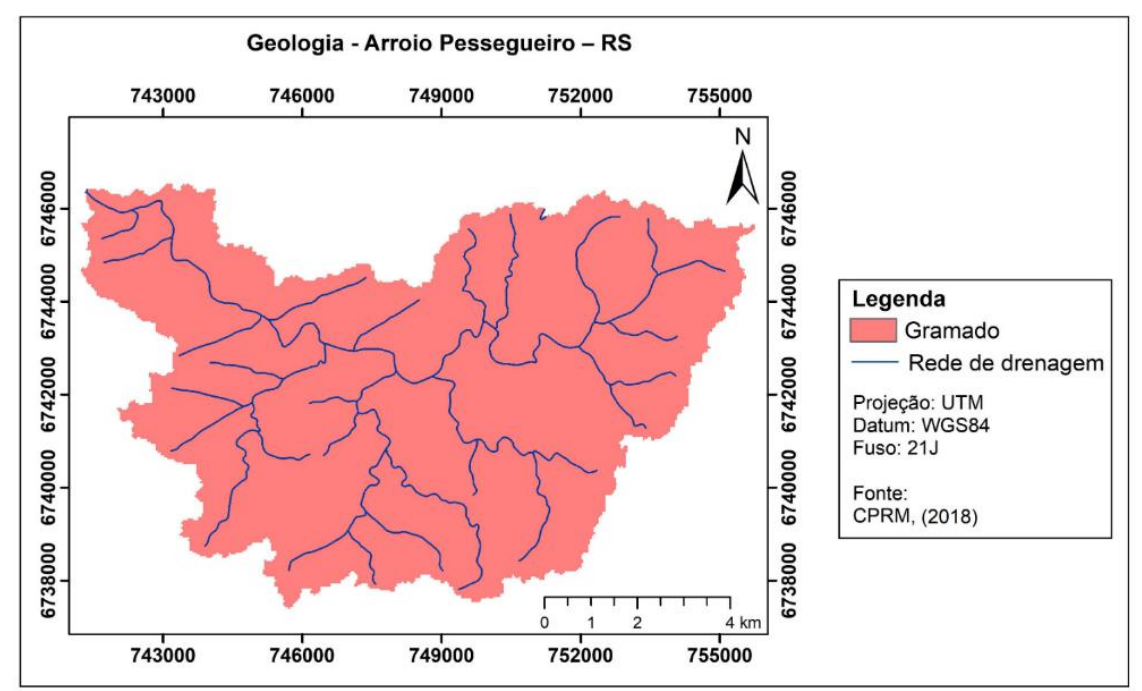

A geomorfologia da área de estudo destacou-se pela: Serra Geral e Planalto dos Campos Gerais. A Formação Serra Geral é constituída de derrames basálticos continentais (Continental Flood Basalts), que formam uma das grandes províncias ígneas do mundo (SAUNDERS et al., 1992). De acordo com Radam Brasil (1986), o Planalto dos Campos Gerais foi desenvolvido sobre as formações vulcânicas ácidas, sendo marcado por colinas onduladas separadas por vales alargados estabelecidos por sucessivas etapas de dissecação que deixaram rupturas de declive e pequenos desníveis (Figura 6).

Figura 6: Geomorfologia da sub-bacia hidrográfica do Arroio Pessegueiro - RS.

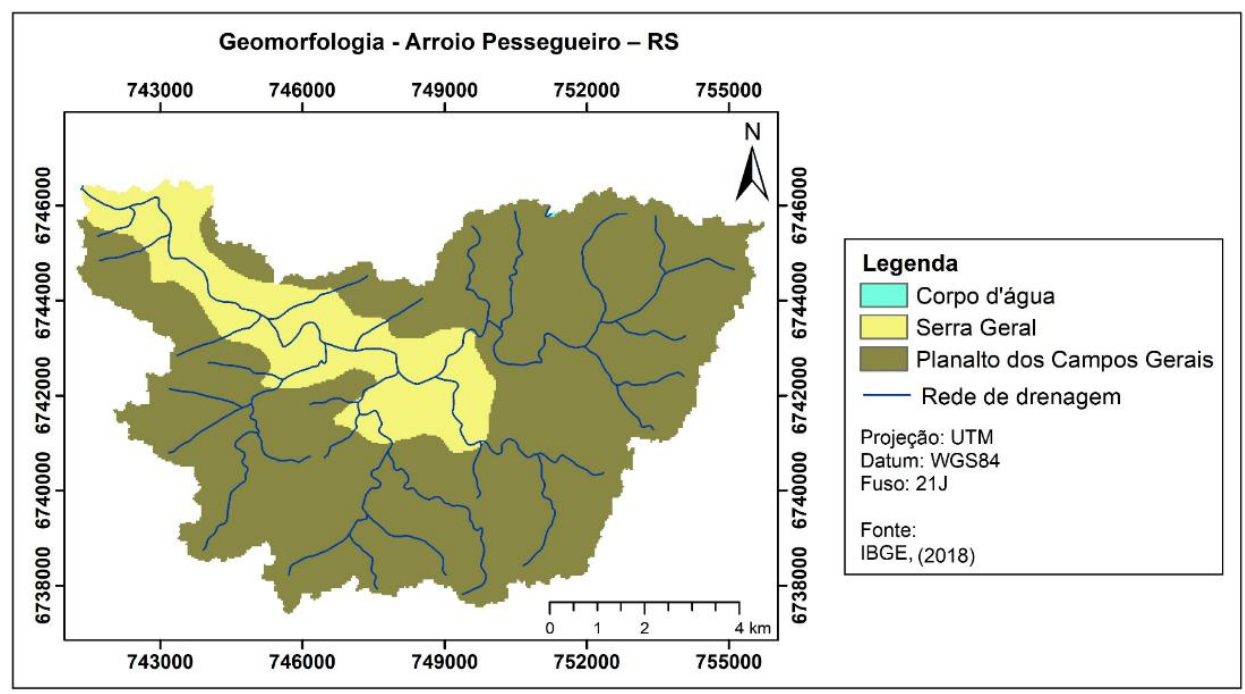

O mapeamento da fragilidade potencial da sub-bacia hidrográfica do Arroio Pessegueiro, foi obtida por meio da sobreposição dos mapas de solo, geologia, geomorfologia e declividade 
(Figura 7).

Figura 7: Fragilidade potencial na sub-bacia hidrográfica do Arroio Pessegueiro - RS.

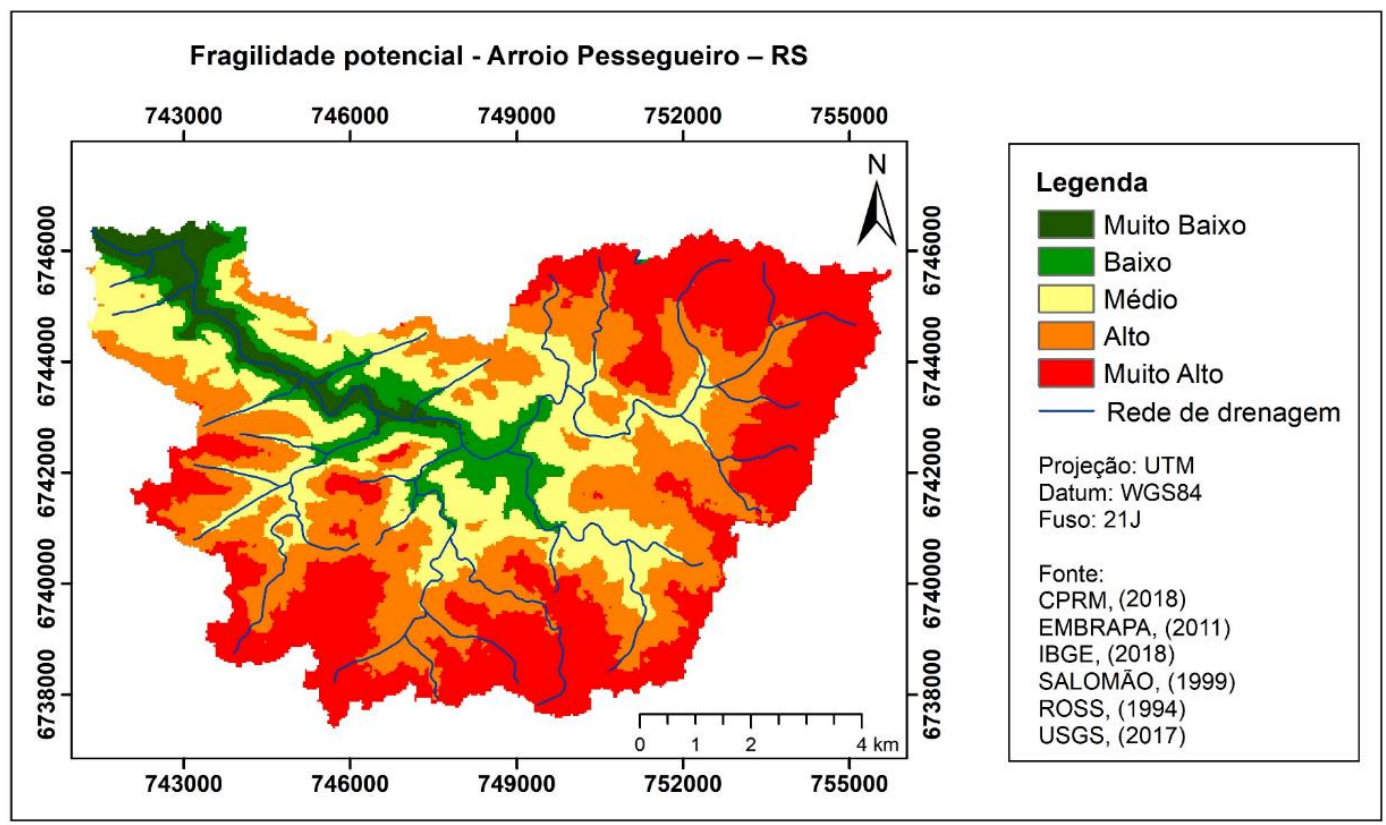

A fragilidade potencial tem como propósito diagnosticar, dentro dos aspectos físicos, o comportamento natural do ambiente em seu equilíbrio dinâmico. Desta forma, as áreas de fragilidade ambiental potencial muito baixa e baixa na sub-bacia do Arroio Pessegueiro destacaram-se em menor porção na região central e noroeste com 364,11ha e 622,43ha respectivamente; totalizando $11,73 \%$. Estas áreas estão associadas às florestas, no qual contribuem para estabelecer o equilíbrio ambiental, minimizando o risco à erosão relacionado aos fatores naturais na sub-bacia em estudo. A unidade geomorfológica presente foi a Serra Geral, que conforme Lemos (2014) são propícias ao desenvolvimento e preservação florestal. Sobre a geologia há o predomínio de fácies Gramado.

A fragilidade média totalizou 1.958,62ha (23,30\%), estando presente na Serra Geral e Planalto dos Campos Gerais. Silva (2015), obteve valores próximos quanto a fragilidade considerada média (26\%) nas de Área de Proteção Ambiental (APA) no Rio Vacacaí Mirim/RS. A fragilidade considerada como muito alta e alta, pode ser notada em quase toda à extensão da área de estudo totalizando $2.854,70$ ha $(33,96 \%)$ e $2.607,52 \mathrm{ha}(31,01 \%)$ respectivamente. Destacam-se principalmente nas declividades de $0-3 \%$ (relevo plano) e 3-8\% (relevo suave ondulado) respectivamente. Mesmo nas áreas com menor declividade, a tipologia do solo foi determinante para a classificação de fragilidade potencial alta e muito alta na sub-bacia hidrográfica do Arroio Pessegueiro. O neossolo litólicos eutróficos são altamente suscetíveis ao processo erosivo, que de acordo com Cunha et al. (2013) são solos jovens, rasos e pouco desenvolvidos, que apresentam minerais primários na sua composição, baixa profundidade e baixo grau de intemperização. Ainda segundo Bockheim (2015) os neossolos litólicos apresentam limitação para o desenvolvimento radicular das plantas. Tanto na fragilidade 
potencial muito alta e alta, a unidade geomorfológica presente é do Planalto dos Campos Gerais.

A fragilidade ambiental emergente, além de levar em consideração os elementos naturais do mapa de fragilidade ambiental potencial (solo, geologia, geomorfologia e declividade), considera-se também o mapa do uso e cobertura da terra, no qual caracteriza-se pelas intervenções do homem no meio ambiente (Figura 8).

Figura 8: Fragilidade emergente na sub-bacia hidrográfica do Arroio Pessegueiro - RS.

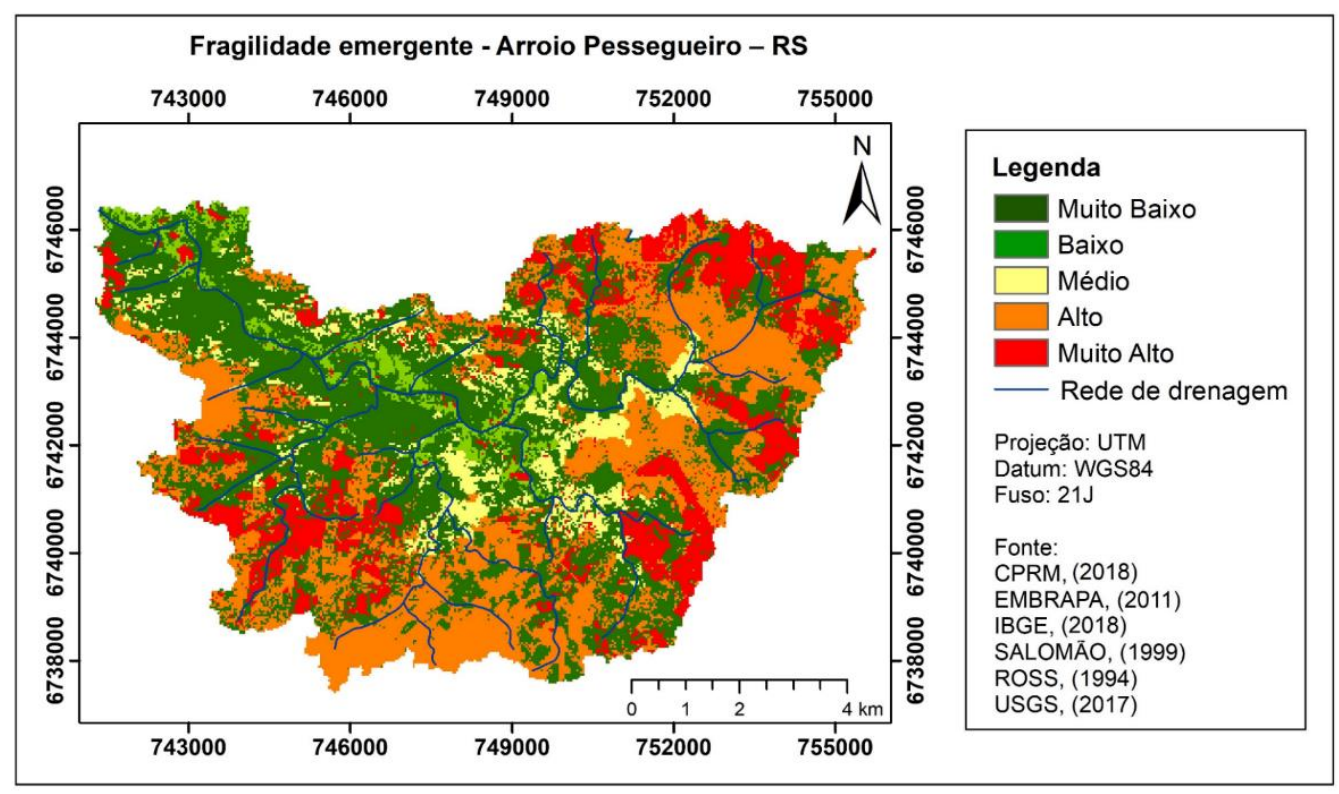

A fragilidade ambiental emergente muito baixa e baixa localizam-se nas áreas onde a há presença da cobertura vegetal (florestas) e nos fundos de vale, totalizando 3.764,04ha $(44,77 \%)$ e 278,13 ha $(3,31 \%)$ respectivamente. Estas áreas possuem grau de proteção alto devido à reduzida ação antrópica. As florestas favorecem a infiltração das águas da chuva e reduz o risco do escoamento concentrado na superfície. Conforme Vogelmann et al. (2015) as florestas têm alto grau de proteção para o solo, já que a vegetação proporciona cobertura devido ao seu dossel, extratos inferiores a matéria orgânica depositada acima do solo.

Para a fragilidade emergente média averiguou-se o total de 593,26ha (7,06\%), destacando-se principalmente nas áreas onde predomina o campo. O campo possui um grau de proteção, pelo fato da vegetação ainda estar presente, mesmo sendo rasteira, a mesma contribui na cobertura ao solo.

$\mathrm{Na}$ porção sul e leste da área de estudo a fragilidade emergente destaca-se por ser alta $(2.538,22$ ha $-30,19 \%)$ e muito alta $(1.233,73$ ha $-14,67 \%)$. Padilha et al. (2013), também encontraram a classe determinada como forte fragilidade ambiental emergente como a segunda classe mais representativa na bacia hidrográfica do Arroio Grande/RS com 24,17\%. Estas áreas com fragilidade alta e muito alta, ocupam praticamente as extensões que remetem às áreas solo exposto e agricultura; estando associadas as declividades de $0-3 \%$ (relevo plano) e $3-8 \%$ (relevo suave ondulado), respectivamente. 0 solo exposto é 
suscetíveis à ação direta dos agentes erosivos, o que provoca o assoreamento dos cursos d' água. Deste modo, a área em questão deve ser monitorada, pois além de possuir uma alta fragilidade, deve-se observar qual é o tipo de uso e manejo que está sendo realizado, bem como compreender os elementos que compõe o solo e suas características, permitindo assim o entendimento da base para o correto manejo, sem acarretar prejuízo ao meio ambiente.

\section{CONCLUSÃO}

Por meio da classificação da fragilidade ambiental potencial, foi possível observar que a subbacia hidrográfica do Arroio Pessegueiro apresenta fragilidade potencial muita alta a média, totalizando 5.462,22ha. Quanto a fragilidade ambiental emergente destacou-se a baixa fragilidade com 3.764,04ha, estas áreas devem ser conservadas e mantidas. Desta forma, compreender as interações dinâmicas que atuam sobre o sistema natural do Arroio Pessegueiro é fundamental, pois serve de subsídio para a gestão da unidade, o que permite restringir e controlar o uso da terra.

Cabe ainda ressaltar que o uso das geotecnologias foi fundamental para o desenvolvimento do estudo, uma vez que, por meio das imagens de satélite foi possível obter o mapa de uso e cobertura da terra, bem como realizar a álgebra de mapas, no qual se mostrou eficaz para identificação da influência de cada componente no mapa final da fragilidade ambiental potencial e emergente.

Por fim, pesquisas relacionadas as temáticas de fragilidade ambiental contribuem para estudos sobre os recursos naturais e do ordenamento territorial. Considerando assim, a capacidade de suporte dos ecossistemas, no qual estão diretamente relacionadas com as caraterísticas especificas de cada paisagem natural.

\section{REFERÊNCIAS BIBLIOGRÁFICAS}

ALVARES, Clayton Alcarde; STAPE, José Luiz; SENTELHAS, Paulo Cesar; DE MORAES GONÇALVES, José Leonardo; SPAROVEK, Gerd. Köppen's Climate Classification Map for Brazil. Meteorologische Zeitschrift, n. 22, v. 6, p. 711 728, 2014.

ASSAD, Eduardo Delgado; SANO, Edson Eyji. Sistema de Informações Geográficas. Aplicações na agricultura. 2 ed., ver. e ampl. Brasília: Embrapa, 1998. 434 p.

BATISTA, José Pio Granjeiro; DA SILVA, Fernando Moreira. Avaliação da fragilidade ambiental na microbacia do riacho Cajazeiras no semiárido Potiguar. Boletim Goiano de Geografia, v. 33, n. 1, p. 53-72, 2013.

BOCKHEIM, James. Classification and development of shallow soils. Geoderma Regional, v. 6, p. 31-39, 2015.

CÂMARA, Gilberto; MEDEIROS, Jose Simeão de. Geoprocessamento para projetos ambientais: tutorias para cursos. São José dos Campos, SP, 1996. 161 p.

CPRM. Companhia de Pesquisa de Recursos Minerais. Mapa Geológico do Rio Grande do Sul, escala 1:750.000. CPRM, Brasília, 2018. Disponível em: <http://www.cprm.gov.br/publique/media/mapa_rio_grande_sul.pdf>. Acesso em: 10 de nov. 2018.

CUNHA, Elias Rodrigues da; BACANI, Vitor Matheus; AYACH, Lucy Ribeiro. Geoprocessamento aplicado à análise da fragilidade ambiental. Revista da ANPEGE, v. 9, n. 12, p. 89-105, 2013. 
EMBRAPA. Empresa Brasileira de Pesquisa Agropecuária. Sistema Brasileiro de Classificação de Solos. 3 ed. Editores Técnicos: Humberto Gonçalves dos Santos et al. Rio de Janeiro (RJ): Embrapa Solos, 2011. 353 p.

IBGE. Instituto Brasileiro de Geografia e Estatística. 2018. Disponível em: < https://ww2.ibge.gov.br/home/geociencias/recursosnaturais/sistematizacao/sist_doc1.shtm>. Acesso em: 10 de nov. 2018.

LEMOS, Andrea Cristina Conceição. Análise geológico-geomorfológica da Bacia Hidrográfica do Rio Paranhana/RS para o reconhecimento de ambientes vulneráveis. Programa de Pós-graduação em Geografia, Universidade Federal do Rio Grande do Sul, Dissertação de Mestrado. 2014. 102 p.

NASCIMENTO, Marilene Dias do; MOURA, Nina Simone Vilaverde; PENNA, Bernardo Sayão. Fragilidades ambientais da cidade de Santa Maria/RS. Revista Geografar, v. 11, n. 2, p. 67-93, 2016.

MENESES, Paulo Roberto, ALMEIDA, Tati de. Distorções e Correções dos Dados da Imagem. In: Meneses, P. R.; Almeida, T. (Org.). Introdução ao processamento de imagens de sensoriamento remoto. Brasília: CNPQ, 266 p. cap. 6.

MOREIRA, Maurício Alves. Fundamentos do Sensoriamento Remoto e Método de Aplicação. 3o ed. atual. ampl. Ed. UFV. Viçosa, MG, 2005. 320 p.

PADILHA, Damáris Gonçalves; TREVISAN, Mário Luiz; CRUZ, Jussara Cabral. Caracterização da fragilidade ambiental da Bacia Hidrográfica do Arroio Grande-RS como subsídio ao planejamento territorial. In: XVI Simpósio Brasileiro de Sensoriamento Remoto, 2013. Anais... Foz do Iguaçu, INPE, 2013, p. 13-18.

RADAM BRASIL. Folha SH22 Porto Alegre. Instituto Brasileiro de Geografia e Estatística. 1986.

ROSA, Roberto; BRITO, Jorge Luis Silva. Introdução ao Geoprocessamento: Sistema de Informações Geográficas. Uberlândia, Ed. Universidade Federal de Uberlândia, 1996. 104 p.

ROSS, Jurandyr Luciano Sanches. Análise Empírica da Fragilidade dos Ambientes Naturais e Antropizados. In: Revista do Departamento de Geografia, n. 8, FFLCH-USP, São Paulo, 1994.

ROSS, Jurandyr Luciano Sanches; KAWAKUBO, Fernando Shinji; MORATO, Rúbia Gomes; CAMPOS, Kleber Cavaça; LUCHIARI, Aiton. 2005. Caracterização empírica da fragilidade ambiental utilizando geoprocessamento. In: Simpósio Brasileiro de Sensoriamento Remoto, 2005. Anais... Goiânia. INPE, 2005, p. 2203-2210.

SILVA, Jorge Xavier da; ZAIDAN, Ricardo Tavares. Geoprocessamento para análise ambiental. Rio de Janeiro: J. Xavier da Silva. 2001.

SILVA, Franciele da. Zoneamento ambiental da APA do Vacacaí-Mirim de acordo com a análise da Fragilidade SocioambientaL. Programa de Pós-graduação em Geografia, Universidade Federal de Santa Maria, Dissertação de Mestrado. 2015. 149 p.

SAUNDERS, Andrew; STOREY, Michel.; KENT, Ray; NORRY, Michel. Consequences of plume-lithosphere interactions. In: Storey, M., Alabaster, A., Pankhurst, R.J. (eds.). Magmatism and the Causes of Continental Break-up. Bath. Geological Society of London, v. 68, n.1 p. 41-60, 1992

STRECK, Edemar Valdir; KÄMPF, Nestor; DALMOLIN, Ricardo Simão; KLAMT, Egon; NASCIMENTO, Paulo César do; SCHNEIDER, Paulo; GIASSON, Élvio; PINTO, Luiz Fernando Spinelli. Solos do Rio Grande do Sul. 2 ed. ver. e ampl. Porto Alegre: Emater/RS, 2008. p. 222.

USGS. United States Geological Survey. Disponível em: <http://earthexplorer.usgs.gov/>. Acesso em: 17 de set. 2018. 